\title{
Fault Mode Operation Strategies for Dual H-Bridge Current Flow Controller in Meshed HVDC Grid
}

\author{
Ataollah Mokhberdoran ${ }^{\mathrm{a}, *}$, Joan Sau-Bassols ${ }^{\mathrm{b}}$, Eduardo Prieto-Araujo $^{\mathrm{b}}$, \\ Oriol Gomis-Bellmunt ${ }^{\mathrm{b}}$, Nuno Silva ${ }^{\mathrm{c}}$, Adriano Carvalho ${ }^{\mathrm{a}}$ \\ ${ }^{a}$ Department of Electrical and Computer Engineering of University of Porto, Rua Doutor Roberto Frias, \\ 4200-465 Porto, Portugal \\ ${ }^{b}$ CITCEA, Departament dEnginyeria Elctrica, Universitat Politcnica de Catalunya, Barcelona, Spain \\ ${ }^{c}$ EFACEC Energia Mquinas e Equipamentos Elctricos, S.A, Un. Switchgear 83 Automation, Rua Frederico \\ Ulrich, 3078 4471-907, Maia, Portugal
}

\begin{abstract}
Current flow controllers (CFCs) can remove grid bottlenecks or extend grid operation area by changing amount of power flowing through de transmission lines. This study focuses on behavior of interline $\mathrm{H}$-bridge $\mathrm{CFC}$ in a dc grid in fault condition. In addition to the CFC circuit level fault studies, non-linear and linearized simplified models are developed for system level analysis. The analysis and fault study shows that the interline H-bridge CFC cannot survive during DC transmission line and bus faults due to an overvoltage occurring in its capacitor. Further investigation figures out that this overvoltage cannot be avoided even in presence of fast HVDC circuit breakers. Hence, an improved control system together with circuit level modifications are proposed to improve the CFC post-fault operation and to retain its components from possible damages.
\end{abstract}

Keywords: DC Circuit Breaker, Meshed dc Grid, dc Fault Currents, Current Flow Controller, DC/DC Converter.

\section{Introduction}

As a consequence of development of large offshore wind farms, there is an increasing demand for realization of multi-terminal HVDC (MT-HVDC) grids [1]. The complex form of MT-HVDC grid is identified as meshed HVDC (M-HVDC) grid, which offers interconnection between different geographical areas to increase renewable energy resources diversity and supply reliability [1].

In addition to protection issues, a meshed dc grid might face power flow control problems $[1,2]$. The power flow in M-HVDC grid is controlled by regulating de voltage of converters considering transmission line impedance. Due to grid topology, multiple paths for current

\footnotetext{
*Corresponding author

Email address: mokhber@fe.up.pt (Ataollah Mokhberdoran)
} 
flow between two different nodes may exist. Consequently, some of the lines can be overloaded because of their lower impedances. Current flow controllers (CFCs) can be inserted into the M-HVDC grid to solve this issue [2].

Several variants of CFCs, including modular bidirectional PFC with fault blocking capability [3], switched resistors for power flow control of the short transmission lines, DC/DC converters for long transmission lines [4], floating CFC [5] and thyristor based power flow controllers $[6,7]$ have been proposed in the literature. Furthermore, IGBT based CFCs with the ac grid connection [8], dual H-bridge CFC [9], cascaded and hybrid PFCs [10], double full-bridge DC/DC converters based CFC [11], a multi-port CFC [12] and interline CFC based on coupled inductors [13] have been investigated in recent years.

Among several proposed topologies the interline series connected CFCs without the ac grid connection are more attractive due to their lower voltage rating, power losses and implementation costs [2]. Particularly, the H-bridge based floating CFC topology with reduced number of switches has several technical superiorities [5]. Although the modeling and control principles of the interline CFC has been scrutinized [2], its behavior during a dc fault has not been considered, yet.

The present paper analyzes behavior of the interline dual H-bridge CFC during M-HVDC grid faults. The system and the circuit level analysis confirms the vulnerability of CFC against short circuit faults in M-HVDC grid even in presence of fast de circuit breakers (DCCBs) and fast protection schemes. To overcome this issue, the CFC control system and its circuit topology are improved. The performance of CFC based on the proposed methods are validated through simulation studies.

\section{Interline CFC with Reduced Switch Number}

The topology of CFC under study is depicted in Fig. 1(a) [5, 9]. The CFC can be placed between two lines and a dc bus to control the current in one line by charging and discharging its capacitor and exchanging power between two lines.
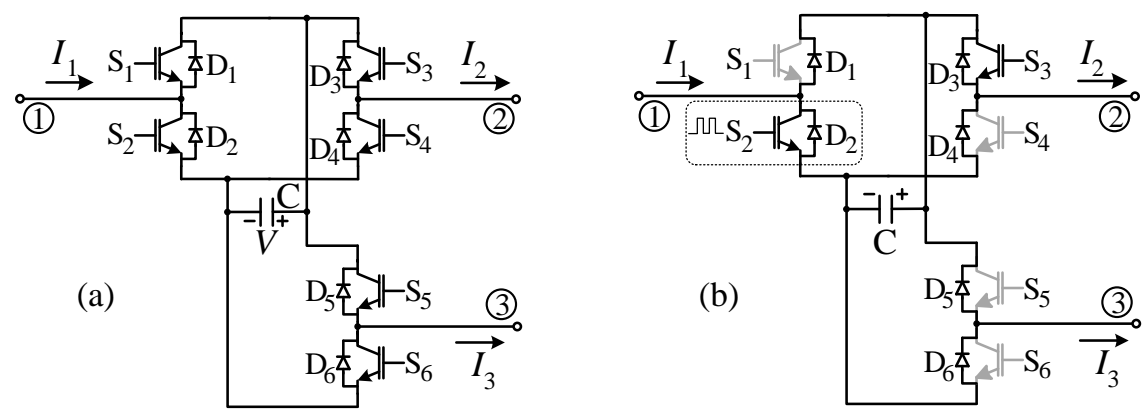

Figure 1: (a) The topology of H-bridge based interline CFC topology with reduced number of switches [5], (b) Switch states to control $I_{12}$ 


\subsection{Normal Operation}

Depending on current direction, the desired voltage can be generated by selecting a suitable set of states of switches. Table 1 shows the switch sates for both negative and positive currents [2]. The capacitor voltage is represented by $V$ in Table I. The current can be controlled using a PI and a second order compensator. The linearized average model of the CFC represented by a couple of voltage sources can be used to design the current control system [2]. As shown in Fig. $1, I_{1}, I_{2}$ and $I_{3}$ are the currents flowing through terminal 1, 2 and 3 of the CFC, respectively. Based on the switching states in [2], $I_{2}$ can be controlled by applying PWM signal to $\mathrm{S}_{2}$ if $I_{1}$ is incoming and $I_{2}$ and $I_{3}$ are outgoing currents. As shown in Fig. 1(b), $S_{1}, S_{4}, S_{5}$ and $S_{6}$ and are opened and $S_{3}$ is closed. A generic control system of $\mathrm{CFC}$ including a PI controller, a second order compensator and a filter is shown in Fig. 2.

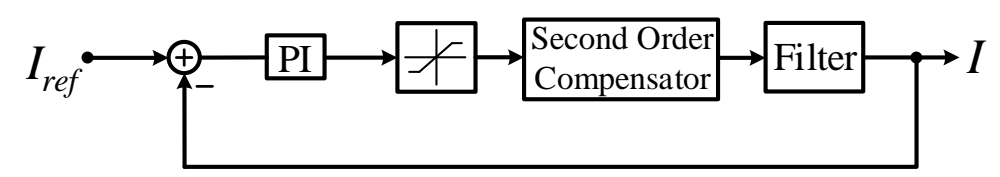

Figure 2: Generic control system of the interline CFC [2]

Table 1: Switching states for positive and negative current scenarios [2]

\begin{tabular}{cccccc||cccccc}
\hline \hline \multicolumn{7}{c||}{ Positive currents } & \multicolumn{6}{c}{ Negative currents } \\
\hline Set & $\mathbf{s w}_{\mathbf{1}}$ & $\mathbf{s w}_{\mathbf{6}}$ & $\mathbf{s w}_{\mathbf{2}}$ & $\boldsymbol{V}_{\mathbf{3 1}}$ & $\boldsymbol{V}_{\mathbf{3 2}}$ & Set & $\mathbf{s w}_{\mathbf{3}}$ & $\mathbf{s w}_{\mathbf{4}}$ & $\mathbf{s w}_{\mathbf{5}}$ & $\boldsymbol{V}_{\mathbf{3 1}}$ & $\boldsymbol{V}_{\mathbf{3 2}}$ \\
\hline $\mathbf{1}$ & 0 & 0 & 0 & $-V$ & $-V$ & $\mathbf{9}$ & 0 & 0 & 0 & $+V$ & $+V$ \\
$\mathbf{2}$ & 0 & 0 & 1 & $-V$ & 0 & $\mathbf{1 0}$ & 0 & 0 & 1 & $+V$ & 0 \\
$\mathbf{3}$ & 0 & 1 & 0 & 0 & $-V$ & $\mathbf{1 1}$ & 0 & 1 & 0 & 0 & $+V$ \\
$\mathbf{4}$ & 0 & 1 & 1 & 0 & 0 & $\mathbf{1 2}$ & 0 & 1 & 1 & 0 & 0 \\
$\mathbf{5}$ & 1 & 0 & 0 & 0 & 0 & $\mathbf{1 3}$ & 1 & 0 & 0 & 0 & 0 \\
$\mathbf{6}$ & 1 & 0 & 1 & 0 & $+V$ & $\mathbf{1 4}$ & 1 & 0 & 1 & 0 & $-V$ \\
$\mathbf{7}$ & 1 & 1 & 0 & $+V$ & 0 & $\mathbf{1 5}$ & 1 & 1 & 0 & $-V$ & 0 \\
$\mathbf{8}$ & 1 & 1 & 1 & $+V$ & $+V$ & $\mathbf{1 6}$ & 1 & 1 & 1 & $-V$ & $-V$
\end{tabular}

\section{CFC Integration into the M-HVDC Grid}

\section{1. $M-H V D C$ grid}

M-HVDC grid can be formed by connecting dc sides of more than two converters through transmission lines. Various VSC technologies can be employed in an M-HVDC grid. Modular multilevel converters (MMCs) demonstrate better performance versus other types of converter for HVDC applications. Among various MMC topologies, the half-bridge MMC has less power losses and lower implementation cost. Nowadays, different variants of half-bridge MMC are widely employed by HVDC project developers. [1]. However, the half-bridge MMC is unable to block de short circuit fault current [1]. In an M-HVDC grid, due to the contribution of adjacent transmission lines [14] and significant reduction in faulty transmission line frequency dependent inductive characteristics due to the high frequency components of dc fault current 
[15], the dc fault current can rise up quickly. Hence, the meshed dc grids need to be effectively protected against the dc side faults $[1,16,17]$.

Several protection strategies have been proposed for MT-HVDC and M-HVDC grids [14, 1, 18, 19, 20]. However, fast dc circuit breakers (DCCB) are to be most promising solution for M-HVDC grid. In a system protected by a fully selective protection scheme, every line is equipped with one DCCB at each end. The converter may be protected by either a DCCB at its dc side or an ac circuit breaker at its ac side [18]. A possible arrangement of DCCBs in a fully protected M-HVDC grid is shown in Fig. 3(a). The fast DCCBs such as hybrid (HCB) and solid-state (SSCB) ones employ a current limiting inductor in series with their structure that should be considered in modeling [14, 21].

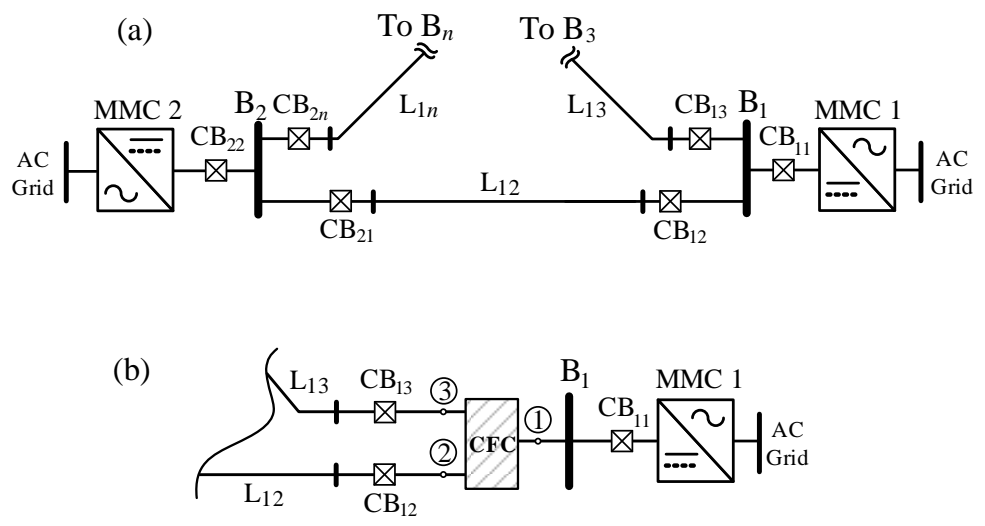

Figure 3: M-HVDC grid (a) DCCB arrangement (b) CFC integration

\section{2. $C F C$ integration into $M-H V D C$ grid}

Typically, the interline CFC is installed between two transmission lines and a dc bus. A possible integration of interline CFC into a dc bus is depicted in Fig. 3(b). The CFC is installed between $\mathrm{L}_{12}, \mathrm{~L}_{13}$ and $\mathrm{B}_{1}$. For sake of protection selectivity, the DCCBs should be relocated as seen in Fig. 3(b). No DCCB is required between the CFC and dc bus, but a disconnector might be needed. Therefore, fault on either $\mathrm{L}_{12}$ or $\mathrm{L}_{13}$ can be cleared by $\mathrm{CB}_{12}$ or $\mathrm{CB}_{13}$ (and remote $\mathrm{DCCBs}$ ) and a fault at $\mathrm{B}_{1}$ can be interrupted by adjacent DCCBs.

\section{CFC During de Fault}

DC fault may occur on adjacent lines or at dc bus. The mentioned incoming and outgoing CFC currents scenario in subsection 2.1 is used to analyze the fault behavior of the CFC from system and circuit points of view. However, this study can be extended to other possible scenarios. The CFC behavior is analyzed when it operates in the normal condition and a dc fault occurs.

\subsection{System level modeling}

The CFC behavior in an HVDC grid during a dc fault is studied considering a threeterminal M-HVDC grid. Fig. 4 shows the three-terminal grid model including the current 
limiting inductors of DCCBs. The parameters of three-terminal grid are illustrated in Table .4 .

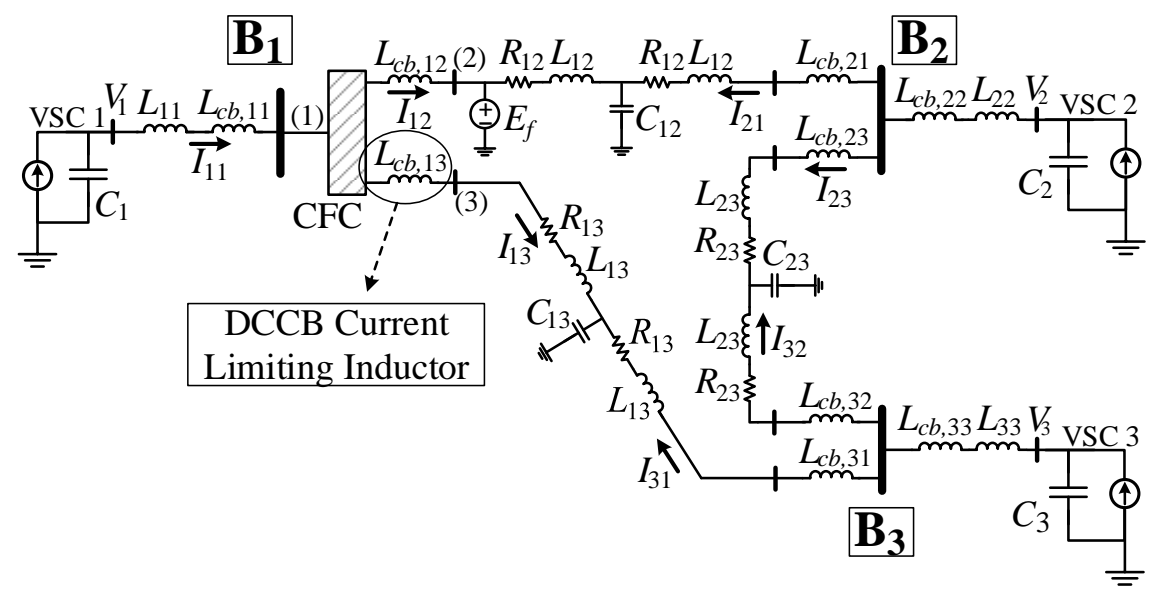

Figure 4: Three-terminal grid including CFC and DCCBs

In this study, the DCCB is modeled as an ideal switch in series with an inductor, which interrupts the current independently of its magnitude after an operation delay defined by $T_{c b}$ upon receiving a trip command [18]. Note that in this study no trip signal is applied to the DCCBs in order to study the fault current behavior. The studied grid has an asymmetric monopole configuration. The simplified average model of VSCs are considered [2] and the cables are modeled as T-equivalent. VSC 1 injects constant power into the grid and VSCs 2 and 3 operate in voltage droop control, whose expressions are described as:

$$
I_{i i}=\frac{P_{i}}{V_{i}}, \quad I_{i}=k_{i}\left(V_{i}^{*}-V_{i}\right)
$$

where, $P_{i}, V_{i}$ and $I_{i i}$ are the power, voltage and current of $\mathrm{VSC} i$, respectively. $V_{i}^{*}$ and $k_{i}$ are the voltage reference and droop constant for VSC $i$, respectively. The fault is modeled as a grounded voltage source with the value of $E_{f}$. In normal condition of the grid the value of $E_{f}$ is equal to the value of line steady-state voltage and it changes to $0 \mathrm{~V}$ upon occurrence of a pole-to-ground dc fault.

The linearized model of grid without the CFC and considering a fault on line 12 very close to terminal 2 of the CFC can be derived assuming that the cable capacitance is shared and included in the node capacitances. Thereafter, the system can be linearized and described by following equations, where subscript 0 indicates the linearization point and $\Delta$ expresses the increment over linearization point:

$$
\begin{gathered}
\frac{\mathrm{d} \Delta V_{1}}{\mathrm{~d} t}=\frac{1}{C_{1}}\left(\frac{\Delta P_{1} V_{10}-\Delta V_{1} P_{10}}{V_{10}^{2}}-\Delta I_{13}-\Delta I_{12}\right) \\
\frac{\mathrm{d} \Delta V_{2}}{\mathrm{~d} t}=\frac{1}{C_{2}}\left(-k_{2} \Delta V_{2}+\Delta I_{12}-\Delta I_{23}\right)
\end{gathered}
$$




$$
\begin{gathered}
\frac{\mathrm{d} \Delta V_{3}}{\mathrm{~d} t}=\frac{1}{C_{3}}\left(-k_{3} \Delta V_{3}+\Delta I_{13}+\Delta I_{23}\right) \\
\frac{\mathrm{d} \Delta I_{21}}{\mathrm{~d} t}=\frac{1}{L_{12}+L_{c b, 21}}\left(\Delta V_{2}-2 R_{12} \Delta I_{21}-\Delta E_{f}\right) \\
\frac{\mathrm{d} \Delta I_{13}}{\mathrm{~d} t}=\frac{1}{2 L_{13}}\left(\Delta V_{1}-\Delta V_{3}-2 R_{13} \Delta I_{13}\right) \\
\frac{\mathrm{d} \Delta I_{23}}{\mathrm{~d} t}=\frac{1}{2 L_{23}}\left(\Delta V_{2}-\Delta V_{3}-2 R_{23} \Delta I_{23}\right) \\
\frac{\mathrm{d} \Delta I_{12}}{\mathrm{~d} t}=\frac{1}{L_{c b, 12}}\left(\Delta V_{1}-\Delta E_{f}\right)
\end{gathered}
$$

where, $I_{i j}$ is the current flowing from bus $i$ to $j . R_{i j}$ and $L_{i j}$ are the T-model resistance and inductance of line $i j$ and $C_{i}$ is the capacitance of bus $B_{i}$. The linearized state-space of dc grid including the CFC can be given by:

$$
\frac{\mathrm{d}}{\mathrm{d} x} \Delta \mathrm{x}=\mathbf{A} \Delta \mathrm{x}+\mathbf{B} \Delta \mathrm{u}
$$

where, $\mathbf{A}$ and $\mathbf{B}$ are $7 \times 7$ and $7 \times 2$ matrices, respectively. $\mathbf{x}$ is the linearized state variables vector and $\mathbf{u}$ is the linearized inputs vector:

$$
\begin{gathered}
\Delta \mathrm{x}=\left(\Delta E_{1}, \Delta E_{2}, \Delta E_{3}, \Delta I_{21}, \Delta I_{13}, \Delta I_{23}, \Delta I_{12}\right) \\
\Delta \mathrm{u}=\left(\Delta P_{1}, \Delta E_{f}\right)
\end{gathered}
$$

The non-linear (NL) model of system can be simulated using the CFC and T-model of transmission lines. The CFC is modeled based on Fig. 1(a). The lumped parameters of adjacent lines are used to design the preliminary control system. The cable and the CFC parameters are illustrated in Table .4. The developed linearized model can be compared to NL model of de grid with and without the CFC. In all the models, a dc fault happens on line 12 at time $\mathrm{t}=4.5 \mathrm{~s} . I_{12}$ for three models including linearized and no-linear models without the $\mathrm{CFC}$ and non-linear model with the CFC is depicted in Fig. 5 . It can be seen that $I_{12}$ reaches approximately $30 \mathrm{kA}$ in $5 \mathrm{~ms}$ in all the models. However, the rate of rise of current is slightly higher in the linearized model as compared to other models.

\subsection{Circuit level analysis}

The three-terminal grid model is used for circuit-level studies. Fig. 6 shows a part of equivalent circuit of system including the CFC. A dc fault can be activated by closing its corresponding switch $\left(\mathrm{F}_{1}-\mathrm{F}_{3}\right)$. The highest rate of rise of the fault current happens when a fault occurs next to the DCCB. In this case, inductance between the CFC and the fault location is equal to the inductance of current limiting inductor of DCCB. Hence, to consider the worst fault scenarios the transmission line faults are placed very close (distance is equal $0 \mathrm{~km}$ ) to the DCCB. All the fault scenarios are studied through the non-linear model from subsection 4.1. 


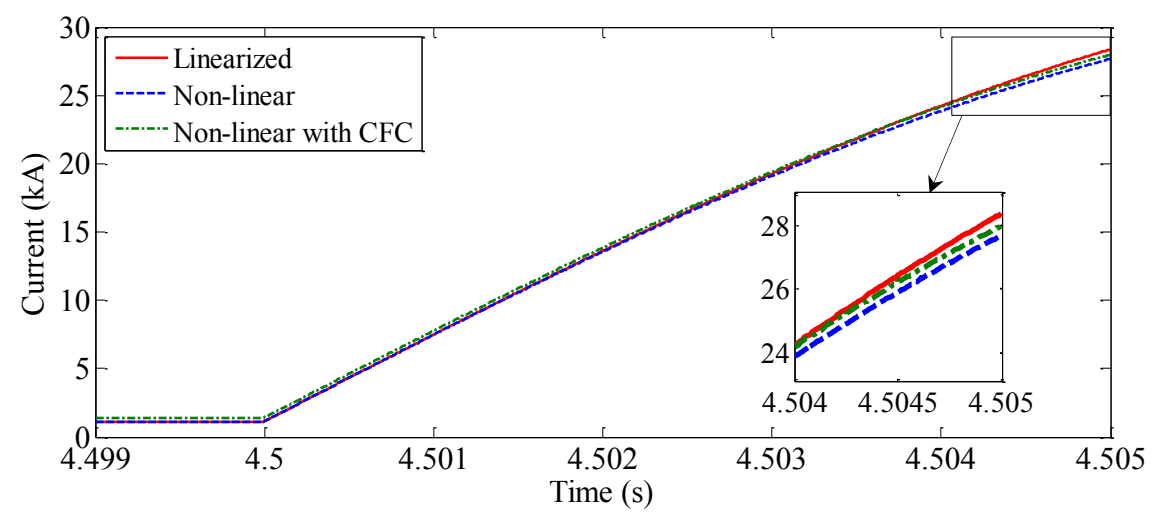

Figure 5: $I_{12}$ in different models with and without the CFC

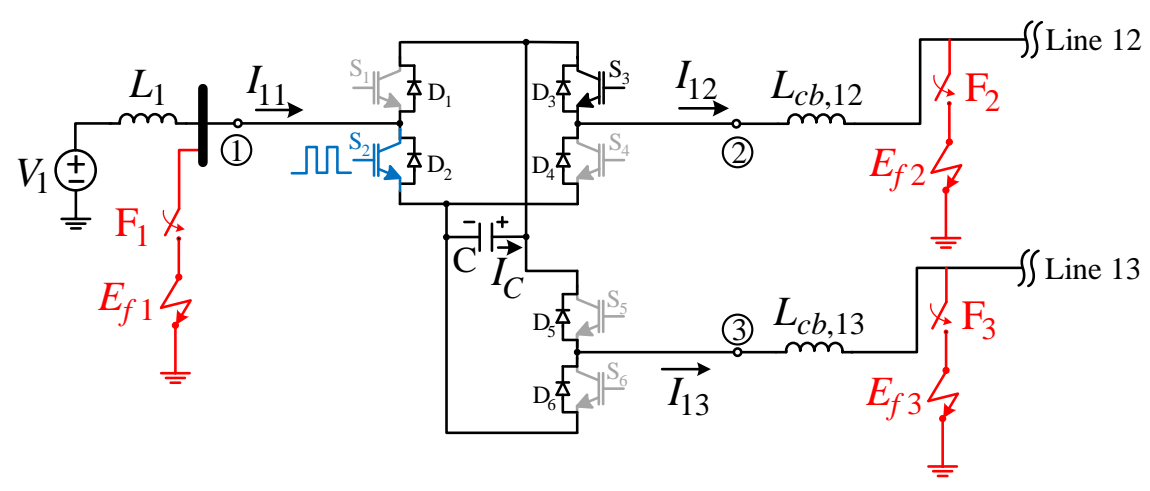

Figure 6: System simplified equivalent circuit during fault

\subsubsection{Fault on line connected to terminal 2 (controlled line)}

The fault occurs next to $\mathrm{CB}_{12}$ and thus very close to terminal 2 of the CFC on line $\mathrm{L}_{12}$. This fault can be activated by closing switch $\mathrm{F}_{2}$ in Fig. 6 . In Fig. $6 L_{1}$ represents the sum of inductances between the $\mathrm{CFC}$ and $\mathrm{B}_{1}$. Initially, $I_{13}$ is positive but its direction is to be reversed due to the fault occurrence on on line $\mathrm{L}_{12}$. Fig. 7 shows various currents and voltages of the CFC and the system.

$V_{C}>0$. In the initial stage of fault and after the direction of $I_{13}$ is reversed, $V_{C}>0$. Therefore, when $\mathrm{S}_{2}$ is closed $I_{1}$ flows through $\mathrm{S}_{2}$ into the CFC capacitor and then via $\mathrm{S}_{3}$ into the fault point. Also, $I_{13}$ flows through $\mathrm{D}_{5}$ and $\mathrm{S}_{3}$ into the fault location. In this stage the capacitor discharges when $\mathrm{S}_{2}$ is closed. When $\mathrm{S}_{2}$ is opened $I_{1}$ flows through $\mathrm{D}_{1}$ and $\mathrm{S}_{3}$ into the fault location whereas $I_{13}$ maintains its path. As it is shown in Fig. 7, when $\mathrm{S}_{2}$ is turned off the flowing current into capacitor falls to zero and capacitor voltage remains constant. However, the capacitor voltage reduces when $\mathrm{S}_{2}$ is closed.

$V_{C}=0$. Previous stage continues until the capacitor voltage falls to zero. Due to antiparallel diodes of $\mathrm{S}_{1}-\mathrm{S}_{6}$ the capacitor cannot be negative and thus its voltage remain approximately zero. In this stage, when $\mathrm{S}_{2}$ is closed $I_{1}$ has two parallel paths to flow: i) through $\mathrm{D}_{1}$ and $\mathrm{S}_{3}$, 

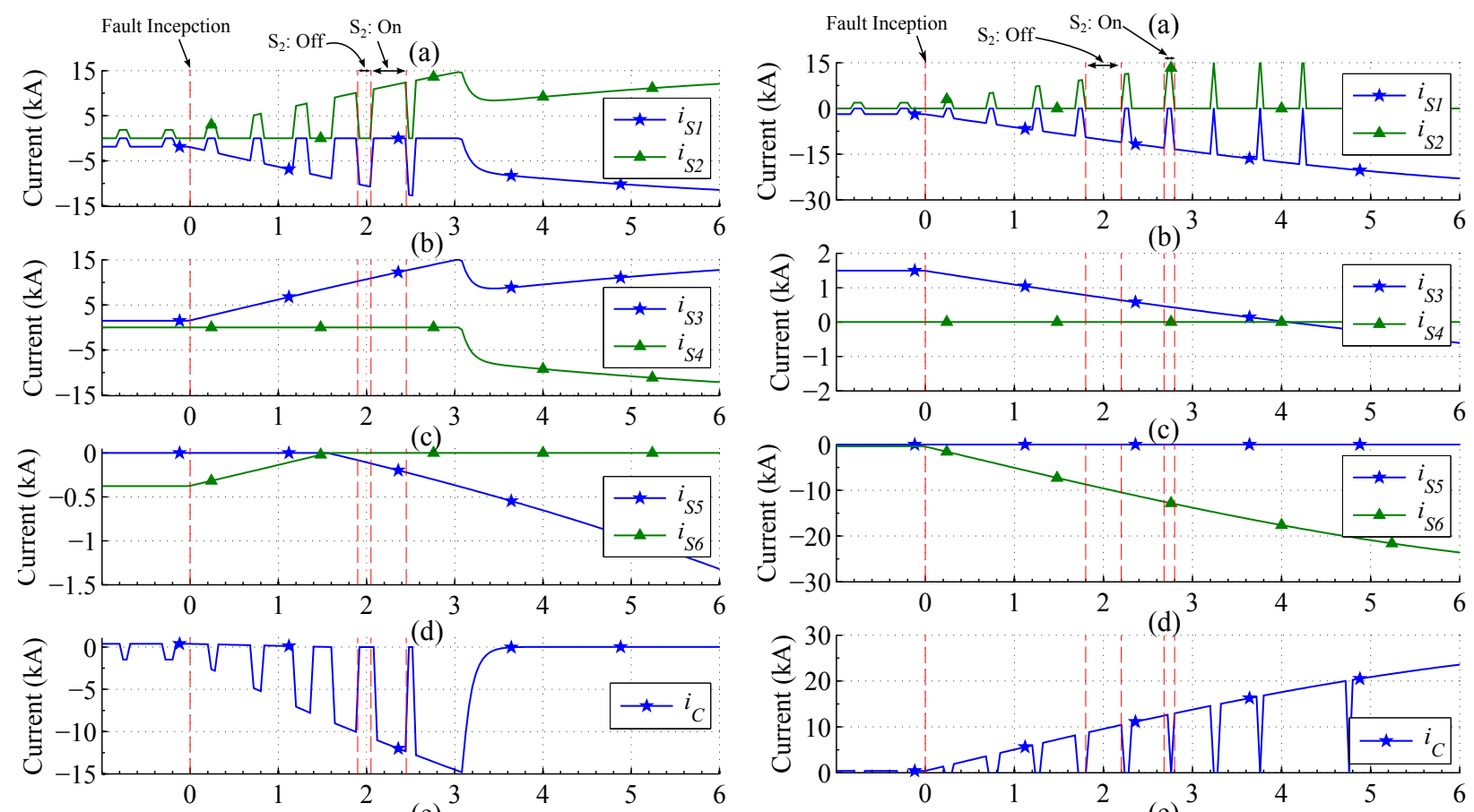

(e)
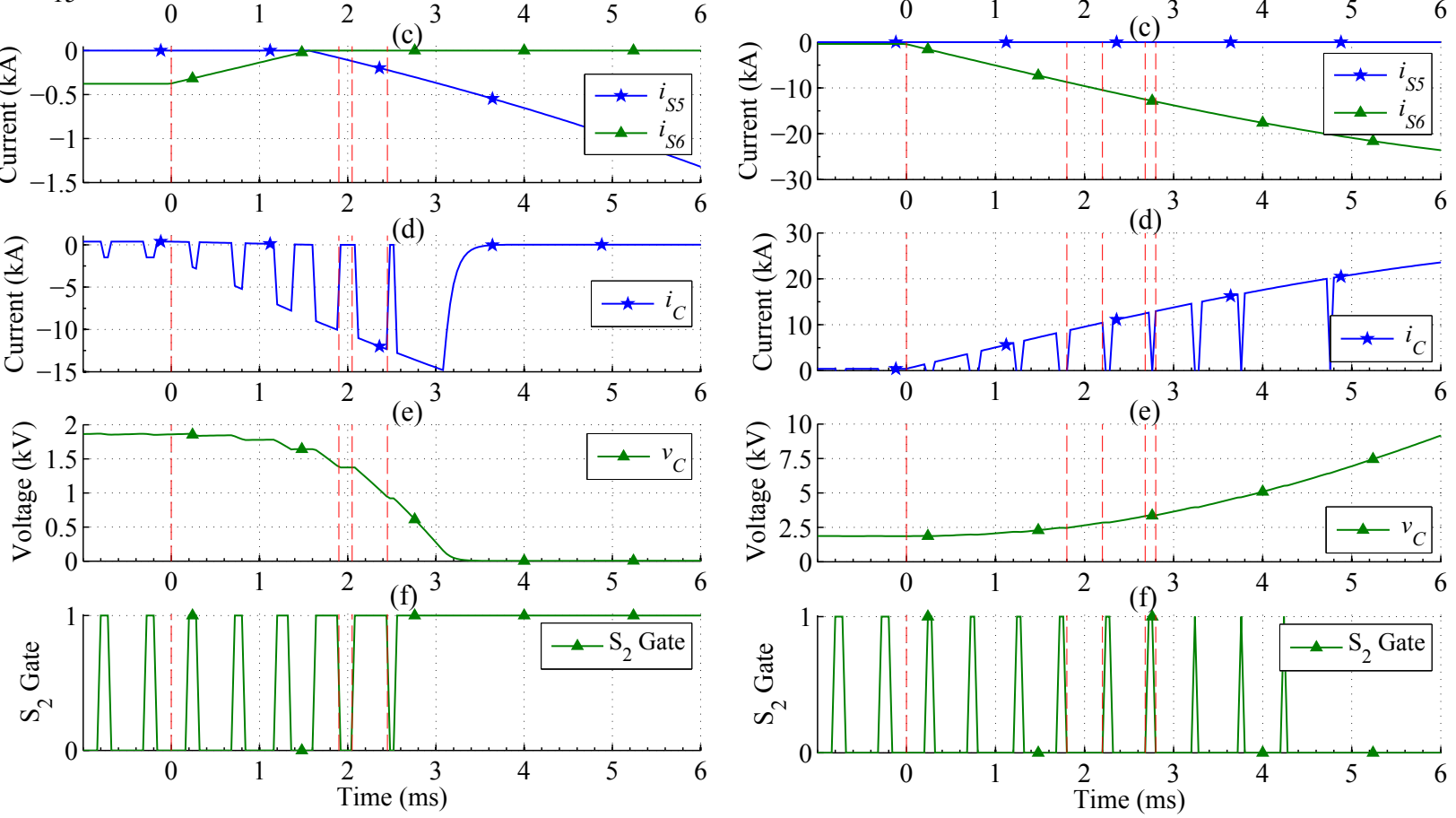

Figure 7: CFC and system waveforms during fault on line 12

Figure 8: CFC and system waveforms during fault on line 13

ii) through $\mathrm{S}_{2}$ and $\mathrm{D}_{4}$. When $\mathrm{S}_{2}$ is opened the CFC behavior is similar to the previous stage. As can be seen in Fig. 7, the CFC control system keeps $\mathrm{S}_{2}$ in on-state after the capacitor voltage falls to zero. Although the capacitor voltage does not increase in this fault scenario, its discharge current may reach undesirable levels (here it reaches $15 \mathrm{kA}$ ). $\mathrm{S}_{1}-\mathrm{S}_{4}$ conduct high fault current, which is out of safe operation area of single commercial switches (here it reaches $12 \mathrm{kA}$.). The most severe case happens when $\mathrm{S}_{2}$ is kept open in this stage, which prevents the fault current from being shared between $S_{1}$ and $S_{2}$ and hence $D_{1}$ must carry whole the current.

\subsubsection{Fault on line connected to terminal 3}

In this case direction of $I_{12}$ is to be reversed. When $S_{2}$ is closed $I_{1}$ flows through $\mathrm{S}_{2}$ and $\mathrm{D}_{6}$ into the fault point on $\mathrm{L}_{13}$. At the same time, $I_{12}$ flows through $\mathrm{D}_{3}$, capacitor and $\mathrm{D}_{6}$ into 


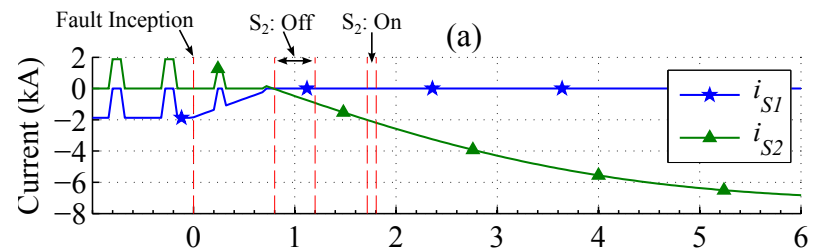

(b)
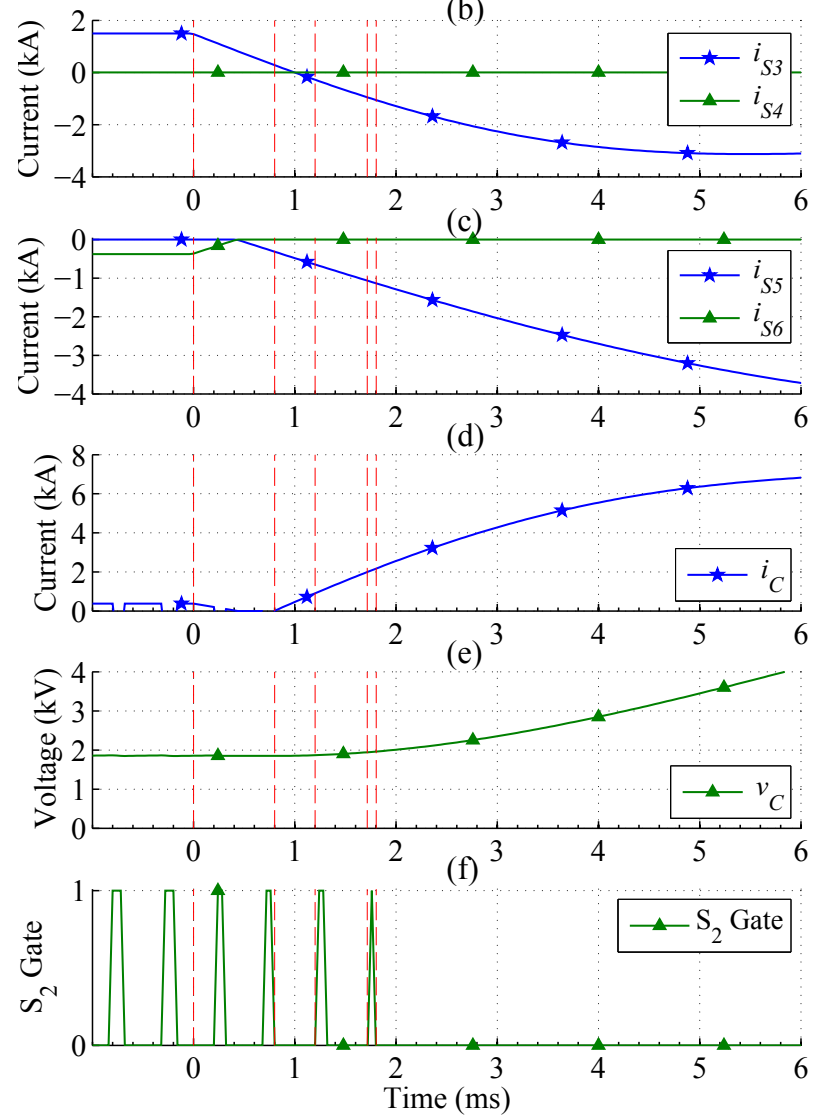

Figure 9: CFC and system waveforms during fault at bus 1

the fault location. When $\mathrm{S}_{2}$ is opened $I_{1}$ flows through $\mathrm{D}_{1}$ into the capacitor and then via $\mathrm{D}_{6}$ into the fault point. The state of $\mathrm{S}_{2}$ does not affect the $I_{12}$ flow path. Hence, the capacitor is continuously charged by the fault current. Therefore, the capacitor voltage increases and can exceed its rated voltage. Fig. 8 shows various currents and voltages of the CFC and system when a fault occurs on $\mathrm{L}_{13}$. As can be seen in the figure, prior to direction reversal of $I_{12}$ the capacitor does not charge continuously. However, after current reversal it is charged up continuously and the rate of rise of capacitor voltage increases. Note that when $\mathrm{S}_{2}$ is closed the flowing current into the capacitor decreases but does not fall to zero. This is due to higher inductance between the CFC and system at its terminal 2. In this scenario $\mathrm{D}_{1}, \mathrm{~S}_{2}$ and $\mathrm{D}_{6}$ are required to carry high current. For instance, the current in $\mathrm{D}_{1}$ and $\mathrm{D}_{6}$ reaches 25 kA. Also, Fig. 8(e) shows that $V_{C}$ reaches $9 \mathrm{kV}$ in $6 \mathrm{~ms}$. 


\subsubsection{Fault at terminal 1 (dc bus)}

When a fault happens at $\mathrm{B}_{1}$, directions of all incoming and outgoing currents are to be reversed. $I_{12}$ flows through $\mathrm{D}_{3}$ and $I_{13}$ flows via $\mathrm{D}_{5}$ and both charge the capacitor and flow to the fault location. Therefore, the capacitor voltage increases. Fig. 9 shows the CFC and line currents and the capacitor voltage during a bus fault. As can be seen in the figure, state of $\mathrm{S}_{2}$ does not have any impact on the fault current after the direction of $I_{12}$ is reversed. In this scenario, $\mathrm{D}_{2}, \mathrm{D}_{3}$ and $\mathrm{D}_{5}$ are stressed. Fig. $9(\mathrm{e})$ shows that the capacitor voltage reaches more than $4 \mathrm{kV}$ in $6 \mathrm{~ms}$.

\subsubsection{Remarks}

The fast protection schemes in M-HVDC grids are expected to detect and clear the DC transmission line and DC bus faults in less than $5 \mathrm{~ms}[14,17,19]$. Hence, the switches and the capacitor can be stressed during this time period. Table 2 illustrates the absolute values of current in different switches and also the value of capacitor voltage at $t=5 \mathrm{~ms}$.

Table 2: Absolute values of different currents and voltages at $t=5 \mathrm{~ms}$

\begin{tabular}{c|ccc}
\hline \hline & Fault on $\mathrm{L}_{12}$ & Fault on $\mathrm{L}_{13}$ & Fault at $\mathrm{B}_{1}$ \\
\hline$\left|i_{s 1}(t)\right|$ & $11 \mathrm{kA}$ & $0 \mathrm{kA}$ & $0 \mathrm{kA}$ \\
\hline$\left|i_{s 2}(t)\right|$ & $11 \mathrm{kA}$ & $22 \mathrm{kA}$ & $6.4 \mathrm{kA}$ \\
\hline$\left|i_{s 3}(t)\right|$ & $11 \mathrm{kA}$ & $0.3 \mathrm{kA}$ & $3.1 \mathrm{kA}$ \\
\hline$\left|i_{s 4}(t)\right|$ & $11 \mathrm{kA}$ & $0 \mathrm{kA}$ & $0 \mathrm{kA}$ \\
\hline$\left|i_{s 5}(t)\right|$ & $0.95 \mathrm{kA}$ & $0 \mathrm{kA}$ & $3.3 \mathrm{kA}$ \\
\hline$\left|i_{s 6}(t)\right|$ & $0 \mathrm{kA}$ & $22 \mathrm{kA}$ & $0 \mathrm{kA}$ \\
\hline$\left|i_{C}(t)\right|$ & $0 \mathrm{kA}$ & $22 \mathrm{kA}$ & $6.4 \mathrm{kA}$ \\
\hline$v_{C}(t)$ & $0 \mathrm{kV}$ & $7 \mathrm{kV}$ & $3.5 \mathrm{kV}$ \\
\hline
\end{tabular}

As can be seen in Table 2, during the short circuit fault on the controlled transmission line (Line 12) the current in $\mathrm{S}_{1}, \mathrm{~S}_{2}, \mathrm{~S}_{3}$ and $\mathrm{S}_{4}$ reaches almost $11 \mathrm{kA}$, which is definitely out of safe operation area of a single semiconductor switch. On the other hand, the short circuit fault on the uncontrolled line (Line 13) causes very large current (almost equal to $22 \mathrm{kA}$ ) in the $\mathrm{S}_{2}$ and $\mathrm{S}_{6}$. In addition, during this type of fault large current (almost equal to $22 \mathrm{kA}$ ) flows though the capacitor. Moreover, the voltage of capacitor increases up to $7 \mathrm{kV}$ when the fault occurs on the uncontrolled transmission line. During the fault at DC bus $1, \mathrm{~S}_{2}$ is more stressed as compared to the other semiconductor switches.

\subsection{Maximum fault current approximation}

As shown in Fig. 7(f), 7(g), 8(f), 8(g), 9(f) and 9(g), the current derivative in the CFC terminals is equal to that of transmission lines in grid without the CFC for similar faults. However, the initial current is not identical for the mentioned cases. Considering the results from subsection 4.1 it can be confirmed that the linearized model considering the high frequency inductances of transmission lines [15] can be used for approximating the maximum fault current at the CFC terminals and consequently in switches and diodes at interruption instant. 


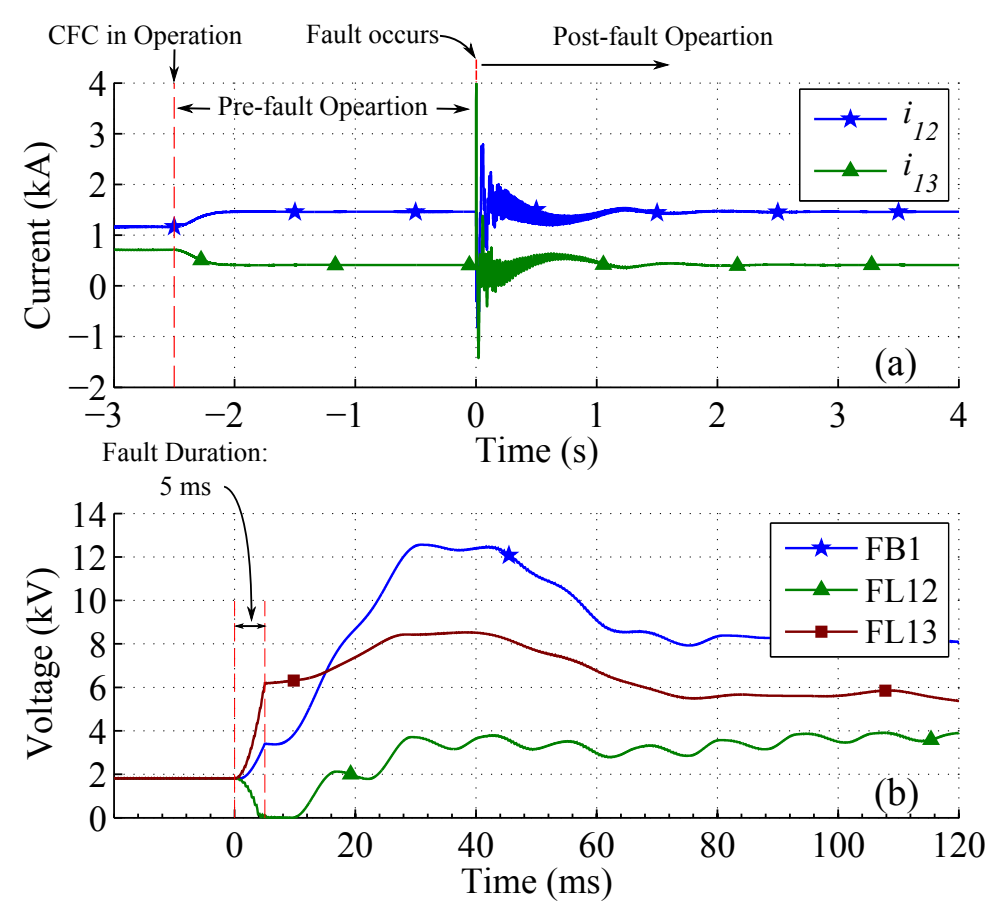

Figure 10: CFC post-fault (a) lines current, (b) capacitor voltage

\subsection{CFC post-fault behavior}

CFC post-fault behavior can be affected due to the controller saturation during the fault condition. Fig. 10(a) shows the CFC currents when a non-permanent short circuit fault happens on line 13 for duration of $5 \mathrm{~ms}$. The CFC regulates $I_{12}$ after the fault is removed. Fig. 10(b) depicts the capacitor voltage for faults on lines 13 (FL13), 12 (FL12) and at bus 1 (FB1). After FLB1 removal the capacitor voltage rises up to $12.5 \mathrm{kV}$, which is several times more than its rated value. Also, the capacitor voltage reaches almost $8 \mathrm{kV}$ after removal of FLB13.

\section{CFC Fault Mode Operation Strategies}

The fault clearing time for fast protection schemes in M-HVDC grid equipped by HCBs considering the fault identification time and peripheral circuits delays lies in range of 3.5-5 ms $[18,22]$. Therefore, the capacitor voltage may exceed its rated value and the semiconductor switches can be damaged by high current even within the short fault clearing time. In this section, an enhanced control system and two fault operation methods are suggested and compared for possible fault scenarios.

\subsection{Enhanced control system}

As shown in Fig. 11 an anti-windup scheme is included the control system. In addition, an internal fault mode activator (FMA) is considered. The FMA activates the fault mode when any switch current exceeds $I_{\max }$. The fault mode stays active for the period of $t_{F M A}$ 
after the current falls below $I_{\max }$. $I_{\max }$ can be determined according to the components characteristics. During system disturbances that may not be detected by protection system, the fault mode may be activated. In other words, the possible destructive impacts of system transients, which are not detected by the system protection scheme as dc faults can be negated by the application of FMA. In order to tune the controller parameters of the CFC, the system under study including the meshed HVDC grid and the CFC is linearized following the same procedure as in [2]. Then, using the linearized model, the controller (including the PI, the second order compensator and the low pass filter) is tuned using modeling software namely MATLAB Simulink to achieve a first order system response. The time constant of the closed loop system response is set to $150 \mathrm{~ms}$, which can be seen in Fig. 10(a). The parameters of control system are illustrated in Table .8.

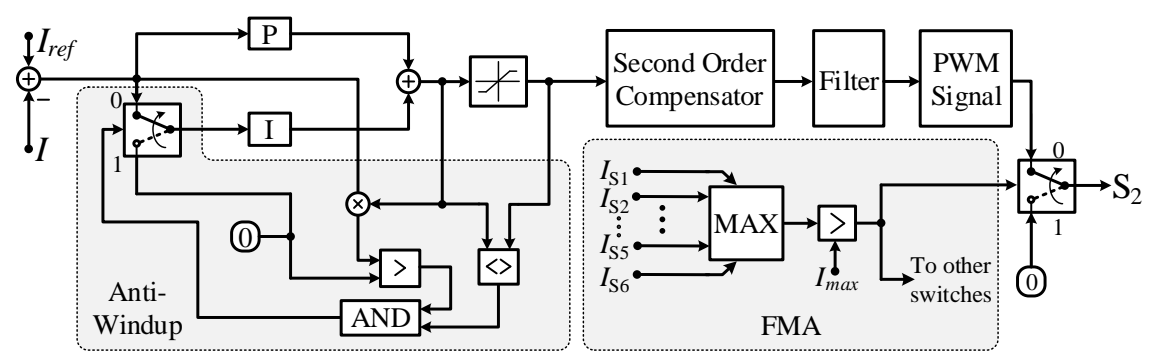

Figure 11: CFC enhanced control system
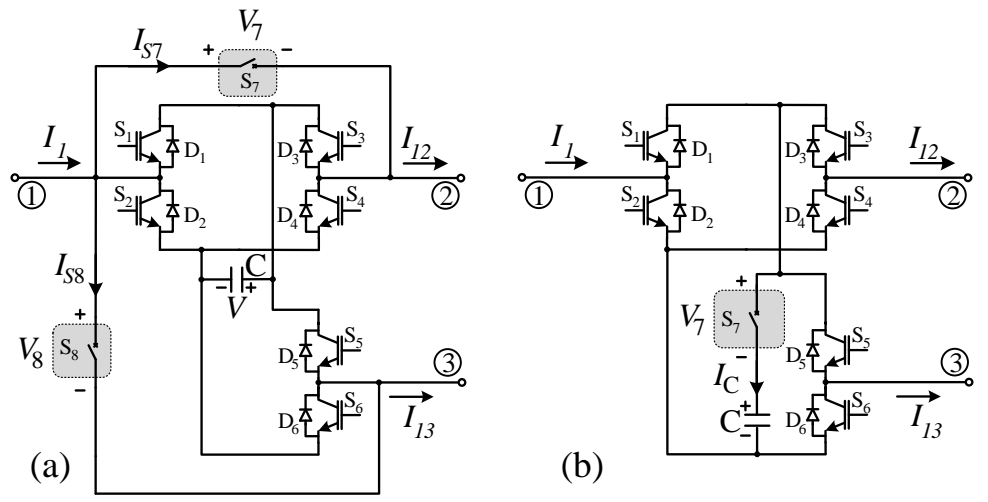

Figure 12: Modified CFC based on: (a) Method 1, (b) Method 2

\subsection{Method 1}

Fig. 12(a) depicts a CFC with parallel bypass branches. The bypass valves $\left(\mathrm{S}_{7}\right.$ and $\left.\mathrm{S}_{8}\right)$ are bidirectional switches. After the fault mode is activated $\mathrm{S}_{2}, \mathrm{~S}_{4}$ and $\mathrm{S}_{6}$ should be opened and then $\mathrm{S}_{1}, \mathrm{~S}_{3}$ and $\mathrm{S}_{5}$ have to be closed (Stage B) to the capacitor current. The next step is closing $S_{7}$ and $S_{8}$ (stage C). Finally, $S_{1}, S_{3}$ and $S_{5}$ are opened (Stage D) and the current is commutated into the parallel branches. Time $t_{C}-t_{B}$ sets the current requirements of $\mathrm{S}_{1}$, $\mathrm{S}_{3}$ and $\mathrm{S}_{5}$. Therefore, it can be minimized to reduce the current capacity of the mentioned 
switches. In addition, $t_{D}-t_{C}$ has to be short enough to prevent the current in the mentioned switches from exceeding its value at $t_{C}$. The current requirement of $S_{7}$ and $S_{8}$ is set by the maximum fault current and the current requirement of $\mathrm{S}_{2}, \mathrm{~S}_{4}$ and $\mathrm{S}_{6}$ depends on $I_{\max }$ in the FMA.

\subsection{Method 2}

As shown in Fig. 12(b) a bidirectional semiconductor switch $\left(\mathrm{S}_{7}\right)$ is placed in series with the capacitor. Voltage rating of $\mathrm{S}_{7}$ is equal to that of capacitor. In normal operation, $\mathrm{S} 7$ is closed. Upon fault mode activation, $\mathrm{S}_{2}, \mathrm{~S}_{4}$ and $\mathrm{S}_{6}$ should be turned off and then $\mathrm{S}_{1}, \mathrm{~S}_{3}$ and $\mathrm{S}_{5}$ have to be turned on (Stage B). Consequently, the capacitor current falls to zero and $\mathrm{S}_{7}$ can be turned off in zero current (Stage C). After $\mathrm{S}_{7}$ is opened $\mathrm{S}_{2}, \mathrm{~S}_{4}$ and $\mathrm{S}_{6}$ can be closed (Stage D). Thereafter, the fault current is shared between all the switches. The current capability for $\mathrm{S}_{1}$ to $\mathrm{S}_{6}$ is equal to half of maximum fault current.

\subsection{Comparison}

In addition to the proposed methods, the standard $\mathrm{CFC}$ can survive during the fault if it is designed according to maximum fault current of system. Table 3 illustrates the number of required switches for different methods. In Table $3, k_{p}$ and $k_{s}$ represent the number of parallel branches and switches in series connection, respectively. Method 2 requires less number of switches as compared to the other methods.

Table 3: Number of switches in various methods

\begin{tabular}{l|ccc}
\hline \hline & Standard & Method 1 & Method 2 \\
\hline CFC's switches & $3 k_{s}\left(k_{p}+1\right)$ & $6 k_{s}$ & $3 k_{s} k_{p}$ \\
Additional switches & 0 & $4 k_{s} k_{p}$ & $2 k_{s}$ \\
Total No. of switches & $3 k_{s}\left(k_{p}+1\right)$ & $2 k_{s}\left(2 k_{p}+3\right)$ & $k_{s}\left(3 k_{p}+2\right)$ \\
\hline
\end{tabular}

\section{Simulations}

Two simulation sets are carried out to validate the functionality of the proposed methods. The three-terminal grid model from section 4.1 and a four-terminal M-HVDC detailed model from [23] are implemented in PSCAD/EMTDC software. To consider the most severe fault situation from the CFC point of view, non-permanent de fault with duration of $5 \mathrm{~ms}$ is considered and the fault is removed before DCCBs act.

\subsection{Three-terminal $M-H V D C$ model}

Three-terminal M-HVDC model under study is depicted in Fig. 4 and the model parameters are illustrated in Table .4. The CFC starts regulating current in line 12 based on its reference value $\left(I_{12 r e f}=1.45 \mathrm{kA}\right)$. A pole-to-ground fault occurs at time $4.5 \mathrm{~s}$. $I_{\max }$ and $t_{F M A}$ are set to $2.8 \mathrm{kA}$ and $2.5 \mathrm{~s}$ in the FMA, respectively. Note that time $t=4.5 \mathrm{~s}$ is shifted to $t^{\prime}=0 \mathrm{~s}$ in the plotted figures. Therefore, the negative times show the pre-fault operation of the system. 

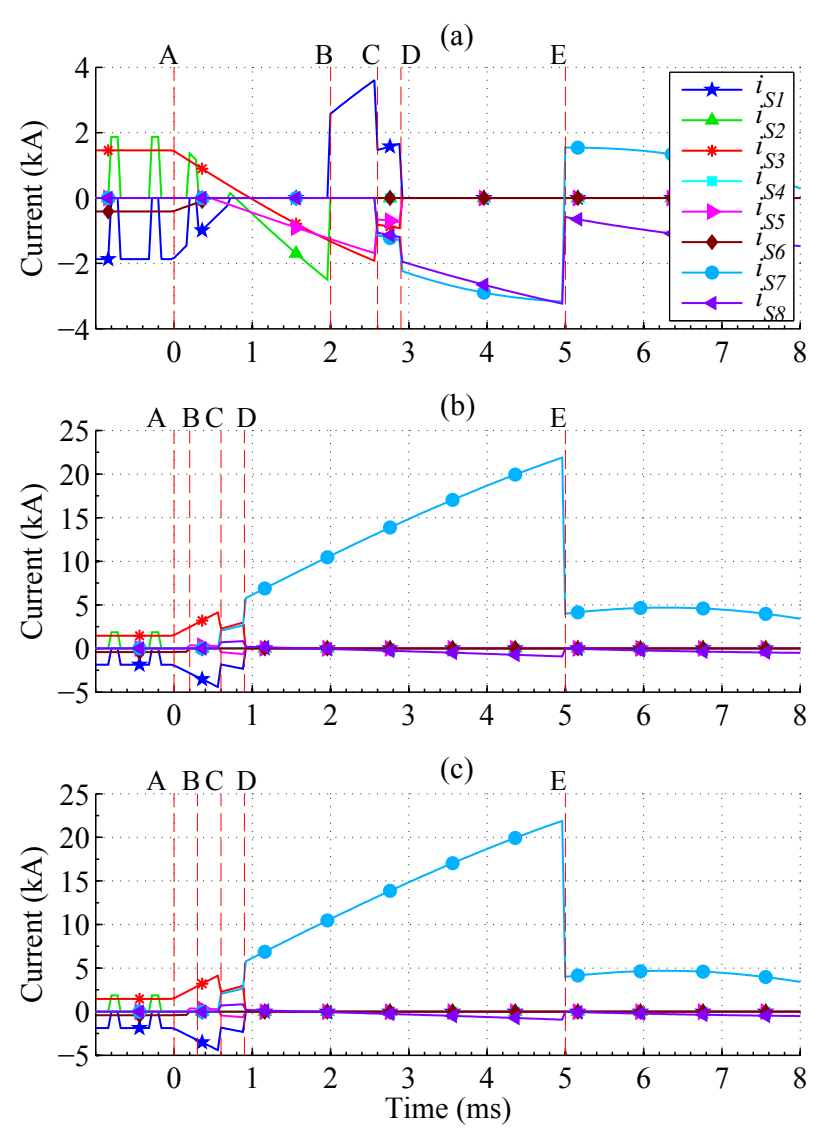

Figure 13: Current in switches of the CFC based on method 2 in three-terminal grid for fault on: (a) bus 1, (b) line 12, (c) line 13
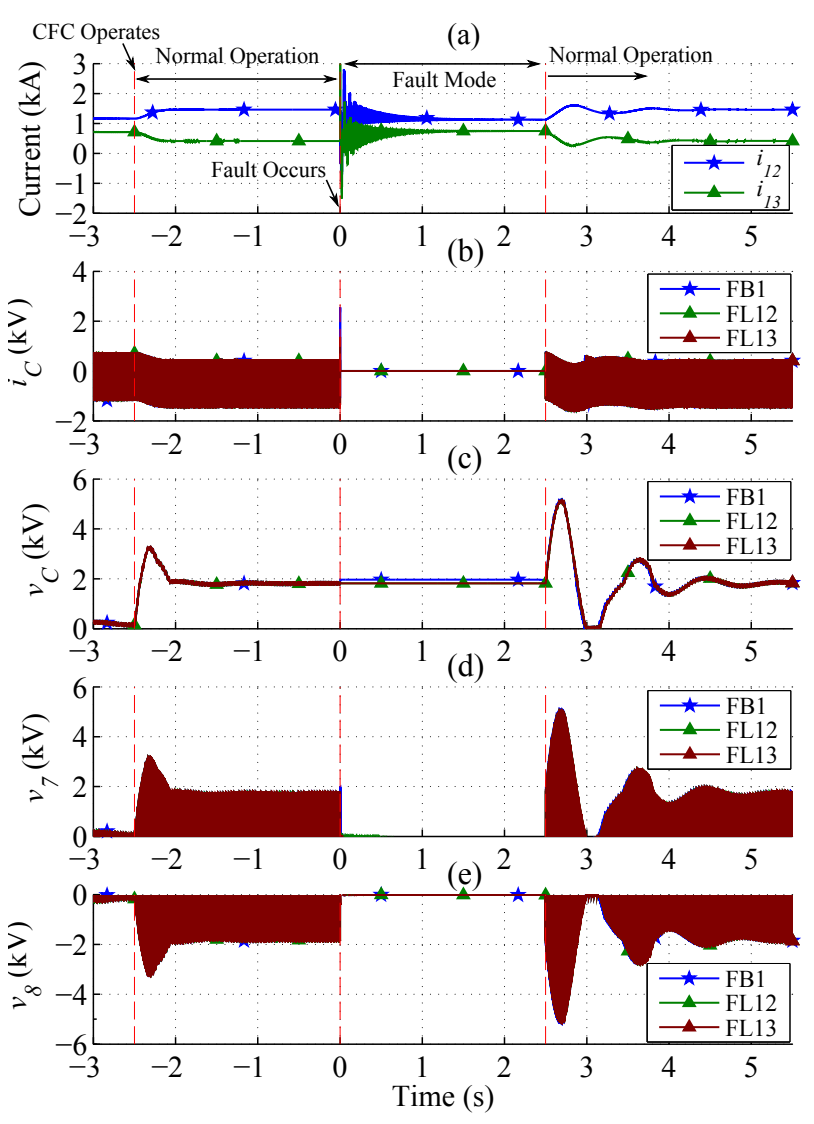

Figure 14: Method 1: (a) line currents, (b) capacitor current, (c) capacitor voltage, (d) $\mathrm{S}_{7}$ and (e) $\mathrm{S}_{8}$ voltage

\subsubsection{Method 1}

Fig. 15 shows the current in semiconductor switches for three fault scenarios. In this figure, A, and E represent fault occurrence and removal instances, respectively. Stages B, C and $\mathrm{D}$ are explained in subsection 5.2. The current in switches during a fault at bus $\mathrm{B}_{1}$ are depicted in Fig. 15(a). The results for faults on lines 12 and 13 are shown in Fig. 15(b) and (c), respectively.

Fig. 14(a) shows the current in lines 12 and 13 in presence of the CFC. Fault occurs at time $0 \mathrm{~s}$ and consequently the CFC enters into the fault mode for $2.5 \mathrm{~s}$ after fault removal. At time $2.505 \mathrm{~s}$, the $\mathrm{CFC}$ returns to normal operation mode and regulates the current in line 12. It can be seen in Fig. 14(b) by employing method 1 the capacitor current during fault is limited below $3 \mathrm{kA}$ for all scenarios. Also, Fig. 14(c) shows that the capacitor voltage remains constant during the fault mode and is also limited below $5.5 \mathrm{kV}$ during the transients when the CFC returns to normal operation. Fig. 14(c) can be compared to Fig. 10 (b) where the capacitor voltage reaches higher values at and after the fault removal. Note that the capacitor voltage rises slightly before fault mode activation in bus fault scenario. This voltage increase is expected based on analysis from subsection 4.2.3. Fig. 14(d) and (e) 

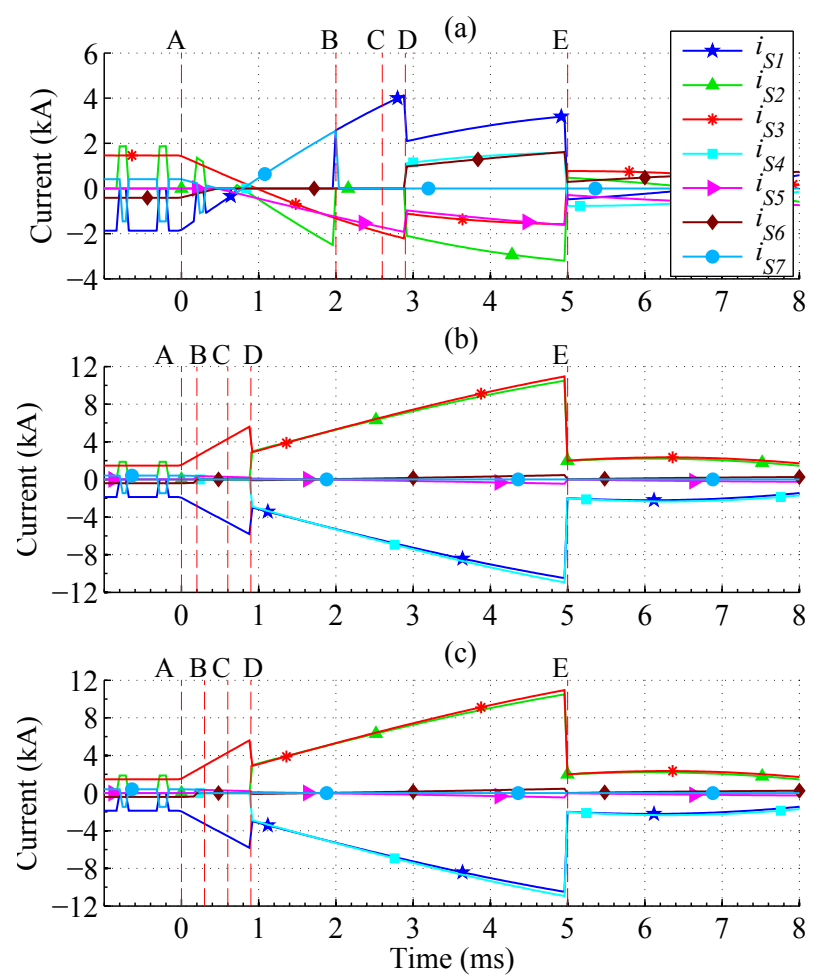

Figure 15: Current in switches of the CFC based on method 2 in three-terminal grid for fault on: (a) bus 1, (b) line 12, (c) line 13
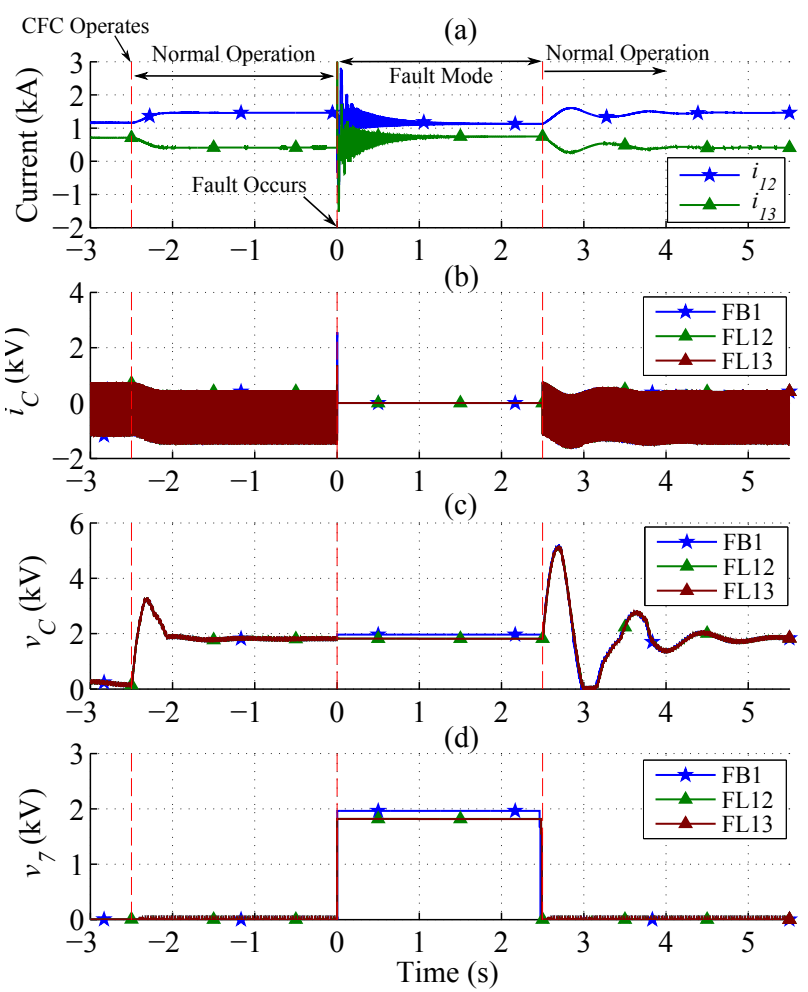

Figure 16: Method 2: (a) line currents, (b) capacitor current, (c) capacitor voltage, (d) $\mathrm{S}_{7}$ voltage

depict the voltage across $S_{7}$ and $S_{8}$, respectively. As it is expected the voltage rating of the mentioned switches is equal to the CFC's other switches. Also, $\mathrm{S}_{7}$ and $\mathrm{S}_{8}$ are opened at time $2.505 \mathrm{~s}$ without any surge voltage since the $\mathrm{S}_{1}, \mathrm{~S}_{3}$ and $\mathrm{S}_{5}$ have been closed.

\subsubsection{Method 2}

The current in switches during a fault at bus $B_{1}$ are depicted in Fig. 13(a). Fig. 13(b) and (c) depicts the results for fault on lines 12 and 13 , respectively. Fig. 16(a) depicts the currents in lines 12 and 13 in presence of the CFC. The CFC currents for method 1 and 2 are identical from system point of view. It can be seen in Fig. 16(b) method 2 limits the capacitor current below $3 \mathrm{kA}$ during the fault for all scenarios. Also, Fig. 16(c) shows that the capacitor voltage remains constant during the fault mode and is limited below $5.5 \mathrm{kV}$ when the CFC returns to normal operation. Comparing Fig. 16(c) to Fig. 10(b) shows significant improvement in the capacitor voltage behavior. Fig. 16(d) depicts the voltage across $S_{7}$. It can be confirmed that the voltage rating of $S_{7}$ is equal to that of the capacitor. Moreover, due to zero current switching of $\mathrm{S}_{7}$ no voltage surge is observed.

\subsection{Four-terminal $M-H V D C$ grid model}

Fig. 17 shows a symmetric monopole four-terminal M-HVDC grid model. One half-bridge MMC is connected to each terminal of the grid. The grid parameters are illustrated in Table 


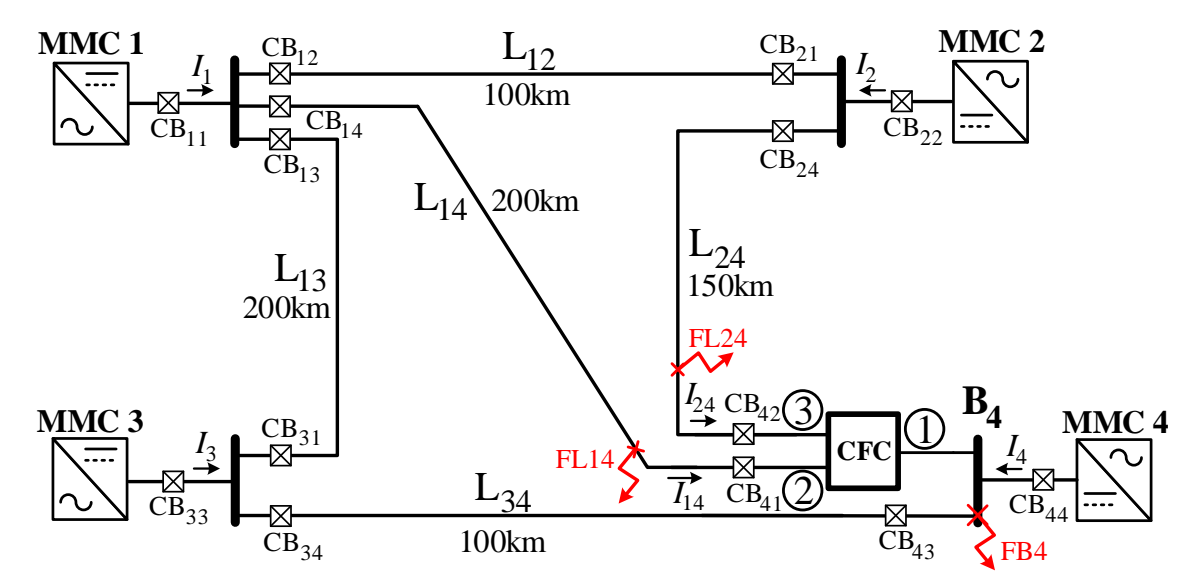

Figure 17: Four-terminal M-HVDC grid equipped with the CFC

.5. Distributed frequency dependent model of XLPE insulated HVDC cable is employed based on physical characteristics, which are illustrated in Table .6 [24]. Due to the system configuration, two CFCs (one for each positive and negative poles) are required. The control system is designed based on lumped parameters of adjacent lines. The lumped cable and the CFC parameters are illustrated in Tables .7 and .8, respectively. The current limiting inductor value for line and converter station DCCBs is set to 50 and $10 \mathrm{mH}$ respectively. The CFC starts its operation at time $t=4.5 \mathrm{~s}$ and increases $I_{14}$ from $451 \mathrm{~A}$ to $745 \mathrm{~A}$. Thereafter, a pole-to-pole fault occurs at time $8 \mathrm{~s}$ (Stage A). $I_{\max }$ and $t_{F M A}$ are set to $2.8 \mathrm{kA}$ and $2.5 \mathrm{~s}$, respectively. Note that time $t=8 \mathrm{~s}$ is shifted to $t^{\prime}=0 \mathrm{~s}$ in the plotted figures.

Due to the better performance of method 2, the results of three fault scenarios including faults at bus 4 (FB4), line 14 (FL14) and line 24 (FL24) for the CFC based on the mentioned method are presented. The current in switches during a fault at bus $\mathrm{B}_{4}$ is depicted in Fig. 18(a). Before fault mode activation $I_{S 1}$ increases rapidly. Upon fault mode activation the stress on switches is reduced by sharing the fault current between $S_{1}$ to $S_{6}$. Fig. 18(a) and (b) depict the results for faults on lines 14 and 24 , respectively. At the FL24 removal instance (Stage E in Fig. 18(c)) current in $\mathrm{D}_{6}$ and $\mathrm{S}_{5}$ reaches almost $8 \mathrm{kA}$. Also, current in $\mathrm{D}_{4}$ and $\mathrm{S}_{3}$ reaches almost $7.5 \mathrm{kA}$ at the FL14 removal instance (Stage E in Fig. 18(b)).

The current in lines 14 and 24 in presence of the CFC is depicted in Fig. 19(a). As can be seen in Fig. 19(b) the maximum capacitor current is almost $3 \mathrm{kA}$ in all fault scenarios. Fig. 19(c) shows that the capacitor voltage remains constant during the fault mode and its post-fault voltage is limited below $2.2 \mathrm{kV}$. As it can be seen in Fig. 19(d) the voltage rating of $\mathrm{S}_{7}$ is equal to that of capacitor and it is turned off without generating surge voltage.

\section{Conclusion}

In this work, the behavior of H-bridge CFC during dc line and bus short circuit faults is investigated. The system level analysis are carried out based on the system linearized and non-linear models. It is identified that the semiconductor switches of the CFC and its capacitor can be damaged due to the high current and voltage caused by the fault and the 

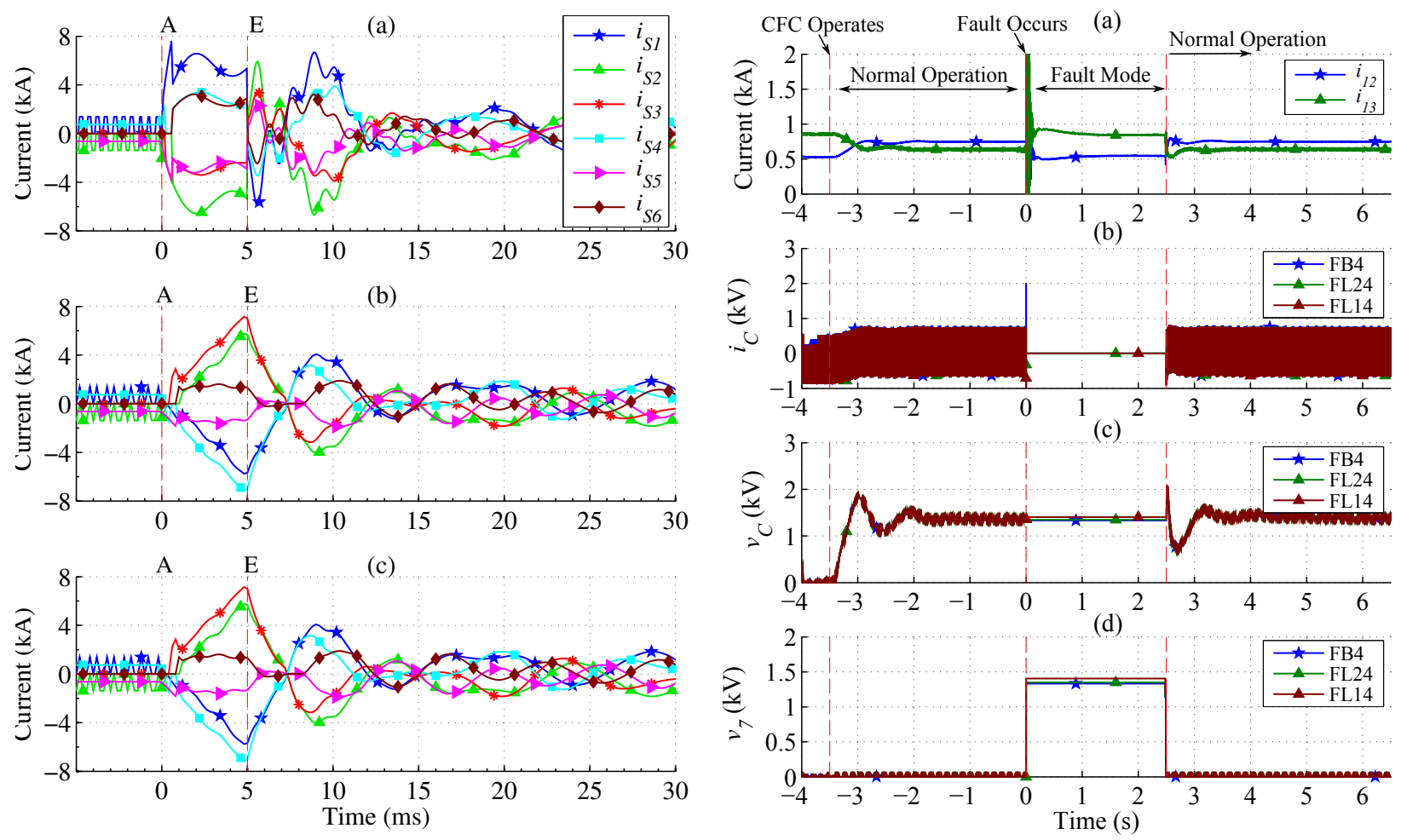

Figure 18: Current in switches of the CFC based on method 2 in four-terminal grid for fault on: (a) bus 4, (b) line $14,(\mathrm{c})$ line 24

Figure 19: Method 2 (in four-terminal grid): (a) line currents, (b) capacitor current, (c) capacitor voltage, (d) $\mathrm{S}_{7}$ voltage

CFC control system behavior, even during short action time of fast protection systems (5 $\mathrm{ms})$. It is also found out that the capacitor voltage increases after fault removal when the CFC starts regulating the current due to the controller action. An improved control system, including a fault mode activator is suggested and employed in this paper. Moreover, two circuit level modifications are proposed and compared. Method 1 employs two parallel bypass branches, which are required to be rated for the maximum fault current at CFC terminals. In method 2 the CFC switches are designed for higher current (equal to half of the maximum fault current at CFC terminals) and a low voltage switch is added in series with the capacitor. A comparison between standard and proposed methods shows that method 2 requires less number of switches. The performance of both proposed methods are validated through two sets of simulations based on three-terminal average and four-terminal detailed M-HVDC grid models. The results are in agreement with the analysis and confirm the functionality of proposed methods.

\section{Acknowledgments}

The research leading to these results has received funding from the People Programme (Marie Curie Actions) of the European Unions Seventh Framework Programme (FP7/20072013) under REA grant agreement $n^{\circ}$ 317221. In addition, this work has been partially 
funded by the Spanish Ministry of Economy and Competitiveness under Project ENE201347296-C2-2-R and Project ENE2015-67048-C4-1-R. This research was co-financed by the European Regional Development Fund (ERDF).

\section{Appendix}

Table .4: Three-terminal test grid parameters

\begin{tabular}{|c|c|c|c|}
\hline \multicolumn{4}{|c|}{ Transmission Lines Parameters } \\
\hline \multirow{2}{*}{ Lumped T-model Parameters } & $\mathrm{R}[\Omega / \mathrm{km}]$ & $\mathrm{L}[\mathrm{mH} / \mathrm{km}]$ & $\mathrm{C}[\mu \mathrm{F} / \mathrm{km}]$ \\
\hline & 0.01105 & 3.245 & 0.382 \\
\hline \multirow{2}{*}{ Length $[\mathrm{km}]$} & Line 12 & Line 13 & Line 23 \\
\hline & 100 & 200 & 200 \\
\hline \multicolumn{4}{|c|}{ VSC Parameters } \\
\hline Bus & 1 & 2 & 3 \\
\hline Capacitance $[\mu \mathrm{F}]$ & 450 & 450 & 450 \\
\hline Power $[\mathrm{MW}]$ & 1200 & - & - \\
\hline$V_{i}^{*}[\mathrm{kV}]$ & - & 300 & 300 \\
\hline Droop Constant $k_{i}[\mathrm{~A} / \mathrm{V}]$ & - & 0.05 & 0.5 \\
\hline \multicolumn{4}{|c|}{ CFC Parameters } \\
\hline Nominal Voltage $[\mathrm{kV}]$ & & & \\
\hline Capacitor $[\mathrm{mF}]$ & & & \\
\hline Switching Frequency $[\mathrm{kHz}]$ & & & \\
\hline
\end{tabular}

Table .5: Four-terminal HVDC system parameters [23]

\begin{tabular}{lcc}
\hline \hline Parameter & Converter 1, 2, 3 & Converter 4 \\
\hline Rated power & $900 \mathrm{MVA}$ & $1200 \mathrm{MVA}$ \\
ac grid voltage & $400 \mathrm{kV}$ & $400 \mathrm{kV}$ \\
Converter ac voltage & $380 \mathrm{kV}$ & $380 \mathrm{kV}$ \\
Transformer, $u_{k}$ & $0.15 \mathrm{pu}$ & $0.15 \mathrm{pu}$ \\
Arm capacitance $C_{\text {arm }}$ & $29.3 \mu \mathrm{F}$ & $39 \mu \mathrm{F}$ \\
Arm reactor $L_{\text {arm }}$ & $84.8 \mathrm{mH}$ & $63.6 \mathrm{mH}$ \\
Arm,resistance $R_{\text {arm }}$ & $0.885 \Omega$ & $0.67 \Omega$ \\
Bus filter reactor $L_{s}$ & $10 \mathrm{mH}$ & $10 \mathrm{mH}$ \\
\hline
\end{tabular}

Table .6: DC cable data [24]

\begin{tabular}{lcccc}
\hline \hline Layer & $\begin{array}{c}\text { Radius } \\
(\mathbf{m m})\end{array}$ & $\begin{array}{c}\text { Resistivity } \\
(\mathbf{m})\end{array}$ & $\begin{array}{c}\text { Rel. } \\
\text { permeability }\end{array}$ & $\begin{array}{c}\text { Rel. } \\
\text { permittivity }\end{array}$ \\
\hline (1) Core & 25.2 & $1.72 \times 10^{-8}$ & 1 & 1 \\
(2) Insulator & 40.2 & - & 1 & 2.3 \\
(3) Sheath & 43.0 & $2.20 \times 10^{-7}$ & 1 & 1 \\
(4) Insulator & 48.0 & - & 1 & 2.3 \\
(5) Armor & 53.0 & $1.80 \times 10^{-7}$ & 10 & 1 \\
(6) Insulator & 57.0 & - & 1 & 2.1 \\
\hline
\end{tabular}

Table .7: Cable lumped PI-model parameters

\begin{tabular}{lccc}
\hline \hline & $\begin{array}{c}\text { Resistance } \\
(\Omega / \mathbf{k m})\end{array}$ & $\begin{array}{c}\text { Inductance } \\
(\mathbf{m H} / \mathbf{k m})\end{array}$ & $\begin{array}{c}\text { Capacitance } \\
(\mu \mathbf{F} / \mathbf{k m})\end{array}$ \\
\hline $\pm 320 \mathrm{kV}$ XLPE Cable & 0.01105 & 2.945 & 32.2 \\
\hline
\end{tabular}


Table .8: CFC parameters

\begin{tabular}{lcc}
\hline \hline & Transfer Function & Value \\
\hline PI & $0.012+\frac{0.398}{s}$ & - \\
Compensator & $\frac{0.3421 s^{2}+1.2978 s+21.5213}{s^{2}+120.5323 s+3207.9071}$ & - \\
Filter & $\overline{0.08 s+1}$ & - \\
Capacitor & - & $10 \mathrm{mF}$ \\
Switching frequency & - & $2 \mathrm{kHz}$ \\
\hline
\end{tabular}

\section{References}

[1] N. Chaudhuri, B. Chaudhuri, R. Majumder, A. Yazdani, Multi-terminal direct-current grids: Modeling, analysis, and control, John Wiley \& Sons, 2014.

[2] J. Sau-Bassols, E. Prieto-Araujo, O. Gomis-Bellmunt, Modelling and control of an interline current flow controller for meshed hvdc grids, IEEE Transactions on Power Delivery 32 (1) (2017) 11-22.

[3] G. J. Kish, P. W. Lehn, A modular bidirectional dc power flow controller with fault blocking capability for dc networks, in: 2013 IEEE 14th Workshop on Control and Modeling for Power Electronics (COMPEL), 2013, pp. $1-7$.

[4] D. Jovcic, M. Hajian, H. Zhang, G. Asplund, Power flow control in dc transmission grids using mechanical and semiconductor based dc/dc devices, in: AC and DC Power Transmission (ACDC 2012), 10th IET International Conference on, 2012, pp. 1-6.

[5] C. D. Barker, R. S. Whitehouse, A current flow controller for use in hvdc grids, in: AC and DC Power Transmission (ACDC 2012), 10th IET International Conference on, 2012, pp. 1-5.

[6] T. Zhang, C. Li, J. Liang, A thyristor based series power flow control device for multi-terminal hvdc transmission, in: Power Engineering Conference (UPEC), 2014 49th International Universities, 2014, pp. $1-5$.

[7] E. Veilleux, B. T. Ooi, Multiterminal hvdc with thyristor power-flow controller, IEEE Transactions on Power Delivery 27 (3) (2012) 1205-1212.

[8] S. Balasubramaniam, J. Liang, C. E. Ugalde-Loo, An igbt based series power flow controller for multi-terminal hvdc transmission, in: Power Engineering Conference (UPEC), 2014 49th International Universities, 2014, pp. 1-6.

[9] S. Balasubramaniam, J. Liang, C. E. UgaldeLoo, Control, dynamics and operation of a dual h-bridge current flow controller, in: 2015 IEEE Energy Conversion Congress and Exposition (ECCE), 2015, pp. $2386-2393$.

[10] K. Rouzbehi, A. Miranian, J. I. Candela, A. Luna, P. Rodriguez, Proposals for flexible operation of multi-terminal dc grids: Introducing flexible dc transmission system (fdcts), in: Renewable Energy Research and Application (ICRERA), 2014 International Conference on, 2014, pp. 180-184.

[11] V. Hofmann, A. Schn, M. M. Bakran, A modular and scalable hvdc current flow controller, in: Power Electronics and Applications (EPE'15 ECCE-Europe), 2015 17th European Conference on, 2015, pp. $1-9$.

[12] M. Ranjram, P. W. Lehn, A multiport power-flow controller for dc transmission grids, IEEE Transactions on Power Delivery 31 (1) (2016) 389-396.

[13] W. Chen, X. Zhu, L. Yao, G. Ning, Y. Li, Z. Wang, W. Gu, X. Qu, A novel interline dc power-flow controller (idcpfc) for meshed hvdc grids, IEEE Transactions on Power Delivery 31 (4) (2016) 1719-1727.

[14] A. Mokhberdoran, A. Carvalho, H. Leite, N. Silva, A review on hvdc circuit breakers, in: Renewable Power Generation Conference (RPG 2014), 3rd, 2014, pp. 1-6.

[15] M. K. Bucher, C. M. Franck, Analytic Approximation of Fault Current Contributions From Capacitive Components in HVDC Cable Networks, IEEE Transactions on Power Delivery 30 (1) (2015) 74-81.

[16] A. Mokhberdoran, A. Carvalho, N. Silva, H. Leite, A. Carrapatoso, A new topology of fast solid-state hvdc circuit breaker for offshore wind integration applications, in: Power Electronics and Applications (EPE'15 ECCE-Europe), 2015 17th European Conference on, 2015, pp. 1-10. 
[17] A. Mokhberdoran, O. Gomis-Bellmunt, N. Silva, A. Carvalho, Current flow controlling hybrid dc circuit breaker, IEEE Transactions on Power Electronics PP (99) (2017) 1-1.

[18] A. Mokhberdoran, N. Silva, H. Leite, A. Carvalho, A directional protection strategy for multi-terminal vsc-hvdc grids, in: 2016 IEEE 16th International Conference on Environment and Electrical Engineering (EEEIC), 2016, pp. 1-6.

[19] A. Mokhberdoran, D. V. Hertem, N. Silva, H. Leite, A. Carvalho, Multi-port hybrid hvdc circuit breaker, IEEE Transactions on Industrial Electronics PP (99) (2017) 1-1.

[20] A. Mokhberdoran, A. Carvalho, N. Silva, H. Leite, A. Carrapatoso, Design and implementation of fast current releasing dc circuit breaker, Electric Power Systems Research 151 (2017) 218 - 232.

[21] A. Hassanpoor, J. Häfner, B. Jacobson, Technical assessment of load commutation switch in hybrid hvdc breaker, IEEE Transactions on Power Electronics 30 (10) (2015) 5393-5400.

[22] W. Leterme, D. V. Hertem, Classification of fault clearing strategies for hvdc grids, in: presented at the 2015 Lund Symposium, Cigre, Lund, 2015.

[23] W. Leterme, N. Ahmed, J. Beerten, L. Angquist, D. V. Hertem, S. Norrga, A new hvdc grid test system for hvdc grid dynamics and protection studies in emt-type software, in: AC and DC Power Transmission, 11th IET International Conference on, 2015, pp. 1-7.

[24] F. Mura, C. Meyer, R. W. D. Doncker, Stability analysis of high-power dc grids, IEEE Transactions on Industry Applications 46 (2) (2010) 584-592. 